\title{
Effects of proprioceptive neuromuscular facilitation- based abdominal muscle strengthening training on pulmonary function, pain, and functional disability index in chronic low back pain patients
}

\author{
Beom-Ryong Kim', Hye-Jin Lee ${ }^{2, *}$ \\ 'Department of Physical Therapy, Graduate School, Sahmyook University, Seoul, Korea \\ ${ }^{2}$ Department of Social Physical Education, Wonkwang University, Iksan, Korea
}

The purpose of this study was to evaluate the effect of abdominal muscle strengthening training (AMST) using proprioceptive neuromuscular facilitation (PNF) on pulmonary function, pain, and functional disability index in chronic low back pain (CLBP) patients. Thirty CLBP patients were randomly assigned to the traditional physical therapy (control) group $(n=15)$ and PNF-AMST group $(n=15)$. Forced expiratory volume at 1 second $\left(\mathrm{FEV}_{1}\right)$ was measured to measure changes in pulmonary function. To measure the degree of pain, a visual analog scale (VAS) was used. The Oswestry Disability Index (ODI) was used to assess the disability level due to low back pain. A paired $t$-test was performed to compare differences within the groups before and after intervention. An independent $t$-test was performed to compare differences between the test and control groups. The level of significance was set at $\alpha=0.05$. Within-group changes in $\mathrm{FEV}_{1}$ were significantly different in the experimental group $(P<0.01)$, and those in VAS and ODI were significantly different in both groups (both $P<0.01$ ). The improvements in $\mathrm{FEV}_{1}$, VAS, and $\mathrm{ODI}$ were significantly greater in the experimental group than in the control group $(P<0.01)$. This study showed that AMST using PNF was effective in enhancing pulmonary function and decreasing pain and functional disability index inpatients with CLBP. We expect it to be useful as one of the programs for CLBP patients in the future.

Keywords: Low back pain, Oswestry Disability Index, Proprioceptive neuromuscular facilitation, Pulmonary function, Visual analog scale

\section{INTRODUCTION}

Low back pain (LBP) is a typical musculoskeletal disorder, with the prevalence of $60 \%-90 \%$ in the general population and $~ 80 \%$ among those who had already experienced LBP at least once (O'Sullivan, 2000). Of patients who have not fully recovered, $15 \%$ experience chronic LBP (CLBP) (Lee et al., 2014a).

Lee et al. (2001) studied various causes of LBP in industrial settings and reported that CLBP is highly related to weakening of abdominal muscles (AMs). Nourbakhsh and Arab (2002) also reported that the weakness of AM was related to LBP. Thus, the weakness of AM (muscles around the waist) is the cause of LBP. In addition, the weakness of AM increases the pelvic anterior tilt and lordosis of the waist, which induce LBP (Rone-Adams et al., 2004). AM contraction increases intra-abdominal pressure, discharges the air to the outside of the diaphragm, and is necessary for bucking for airway clearance. CLBP is difficult due to AM weakness (Bach et al., 1993). Lee et al. (2008) measured muscle activation of forced expiratory volume at 1 second $\left(\mathrm{FEV}_{1}\right)$ and $\mathrm{AM}$ in adults with CLBP, which was lower than in normal adults, and a lumbar stability exercise significantly improved pulmonary function and AM muscle activation, and also reduced pain.

In general, sit-up exercises using various instruments and tools are used to enhance AM (Hildenbrand and Noble, 2004). These
${ }^{*}$ Corresponding author: Hye-Jin Lee (iD https://orcid.org/0000-0002-6840-4162 Department of Social Physical Education, Wonkwang University, 460 Iksan-daero, Iksan 54538, Korea

Tel: +82-63-835-9050, Fax: +82-63-835-5090, E-mail: hjil@wonkwang.ac.kr Received: June 28, 2017 / Accepted: July 28, 2017
This is an Open Access article distributed under the terms of the Creative Commons Attribution Non-Commercial License (http://creativecommons.org/licenses/by-nc/4.0/) which permits unrestricted non-commercial use, distribution, and reproduction in any medium, provided the original work is properly cited. 
exercise methods may help strengthen the AM, but excessive trunk-bending exercise can cause problems such as vertebral compression fractures because of osteoporosis (Ralston et al., 1990) or disc herniation because of an increase in intraspinal pressure (Nachemson, 1981).

However, proprioceptive neuromuscular facilitation (PNF) reduces the load on vertebral bodies when performed in prone, side-lying, and sitting positions. Isometric and isotonic exercises can be performed in neutral positions to prevent damage. Exercises with arms and legs can indirectly activate AM. Kofotolis and Kellis (2006) reported that performing a PNF trunk pattern in a sitting position was effective for treating CLBP and that it improved muscle endurance, flexibility, and functional performance. Yoo et al. (2013) reported that PNF lower extremity pattern training in a prone position was effective for AM activation. Kim et al. (2014) showed an improvement in pain, functional disability, and fear-avoidance belief by applying the PNF coordination pattern in a standing position.

Thus, these studies used PNF for musculoskeletal LBP patients. However, we reasoned that application of patterns that can strengthen AM in various positions would be more effective. The purpose of this study was to evaluate the effect of PNF-AM strengthening training (AMST) on pulmonary function, pain, and functional disability index in CLBP patients.

\section{MATERIALS AND METHODS}

\section{Subjects}

This study was conducted at Design Hospital in Jeonju city from March to August 2016. The subjects were CLBP patients aged 30-40 years who complained of LBP for over 12 weeks. Those with acute pain or persistent severe pain, those with spondylolysis or spondylolisthesis, the presence of abnormal neurologic sensations or muscular paralysis, and subjects who had difficulties in exercise performance due to mental problems or lack of understanding were excluded from the study. Thirty patients who agreed to participate in the study and understoodits purpose were included. These were randomized to the traditional physical therapy (TPT) control group ( $\mathrm{n}=15)$ and the PNF-AMST experimental group $(n=15)$. The characteristics of the participants are summarized in Table 1.

\section{PNF-AMST program}

The PNF-AMST intervention was performed using patterns and techniques to accommodate the level of patients in various
Table 1. General characteristics of subjects

\begin{tabular}{lccc} 
Characteristic & $\begin{array}{c}\text { Experimental group } \\
(\mathrm{n}=15)\end{array}$ & $\begin{array}{c}\text { Control group } \\
(\mathrm{n}=15)\end{array}$ & $P$-value \\
\hline Sex (male:female) & $8: 7$ & $9: 6$ & 1.00 \\
Age (yr) & $39.80 \pm 5.47$ & $39.40 \pm 5.69$ & 0.42 \\
Height (cm) & $168.73 \pm 7.27$ & $168.73 \pm 8.01$ & 0.07 \\
Weight $(\mathrm{kg})$ & $67.60 \pm 9.51$ & $67.07 \pm 9.65$ & 0.19 \\
FEV $_{1}(\mathrm{~L})$ & $3.18 \pm 0.44$ & $3.20 \pm 0.58$ & 0.12 \\
VAS (score) & $6.60 \pm 1.12$ & $6.53 \pm 1.11$ & 0.96 \\
ODI (score) & $33.27 \pm 6.76$ & $33.53 \pm 4.75$ & 0.87 \\
\hline
\end{tabular}

Values are presented as mean \pm standard deviation.

FEV 1 , forced expiratory volume at 1 second; VAS, visual analog scale; ODI, Oswestry Disability Index.

positions for $\mathrm{AM}$ facilitation and strengthening. There was a rest of about $20 \mathrm{sec}$ between sets. Warm-up for $10 \mathrm{~min}$, main exercises for $30 \mathrm{~min}$, cool-down for $10 \mathrm{~min}$ (a total of $50 \mathrm{~min}$ ), 5 times a week for 6 weeks. The detailed PNF-AMST program is described in the table below (Table 2).

\section{TPT program}

TPT was performed as a traditional intervention method for CLBP patients. Hot pack treatment $\left(80^{\circ} \mathrm{C}, 20 \mathrm{~min}\right)$, interfacial current therapy $(2,000-2,500 \mathrm{~Hz}, 20 \mathrm{~min})$, and ultrasound (0.8-1 $\mathrm{MHz}, 10 \mathrm{~min}$ ) were performed for a total of 50 min 5 times a week for 6 weeks.

\section{Forced expiratory volume at 1 second}

$\mathrm{FEV}_{1}$ was measured using a spirometer (Schiller SP-260, Medical Supply Co. Ltd., Dublin, Ireland). Measurements were carried out after sufficient explanation and demonstration of the method to the subject. The measurement indicators measure $\mathrm{FEV}_{1}$ after starting forced vital capacity for $1 \mathrm{sec}$. The pulmonary function test was repeated three times in the sitting position, and the mean value was recorded.

Pain

Pain was assessed using a visual analog scale (VAS, $0-10 \mathrm{~cm}$; 0 means no pain, 10 means severe pain). The examination and retest cross-reliability was $r=0.96$ (Lingjaerde and Føreland, 1998).

\section{Functional disability index}

The Oswestry Disability Index (ODI) is intended to measure the disability level due to LBP. It consists of ten questions: pain intensity, personal care, lifting, walking, sitting, standing, sleeping, sex life, and social life. Depending on performance ability, 6 
levels (0 to 5 points) can be specified: the higher the score, the greater the disability (Fairbank, 2014). The ODI is calculated by dividing the total score by the number of questions answered and multiplying by 100 .

\section{Data analysis}

Statistical analysis was performed using IBM SPSS ver. 18.0 (IBM Co., Armonk, NY, USA). The Shapiro-Wilk test was used to check the normal distribution of data. The paired $t$-test was performed to compare pulmonary function, pain, and ODI values within the groups before and after intervention. The independent $t$-test was performed to compare the test and control groups. The level of significance was set at $\alpha=0.05$.

\section{RESULTS}

\section{Comparison of $\mathrm{FEV}_{1}$ changes}

The changes in $\mathrm{FEV}_{1}$ after 6-week treatment are detailed in Table 3. Within-group changes in $\mathrm{FEV}_{1}$ were significant in the experimental group $(t=-9.56, P<0.01)$ but not in the control group. $\mathrm{FEV}_{1}$ improved more significantly in the experimental group than in the control group $(t=3.19 ; P<0.01 ; 95 \%$ confidence interval [CI], 0.21-0.97).

\section{Comparison of VAS changes}

The changes in VAS after 6-week treatment are detailed in Table 3. Within-group changes were significant in both the experimental group $(t=18.44, P<0.01)$ and the control group $(t=8.50$, $P<0.01)$. VAS was reduced to a greater extent in the experimental group than in the control group $(t=-7.97 ; P<0.01 ; 95 \% \mathrm{CI}$, -2.72 to -1.61$)$.

\section{Comparison of ODI changes}

The changes in $\mathrm{FEV}_{1}$ after 6-week treatment are detailed in Table 3. Within-group changes were significant in both the experimental group $(t=8.99, P<0.01)$ and the control group $(t=18.08$, $P<0.01)$. The reduction in ODI was greater in the experimental group than in the control group $(t=-5.20 ; P<0.01 ; 95 \% \mathrm{CI}$, -10.68 to -4.65$)$.

\section{DISCUSSION}

This study addressed the effect of PNF-AMST on pulmonary function, pain, and functional disability index in CLBP patients. Kim et al. (2009) conducted AMST for 5 days in a sitting position

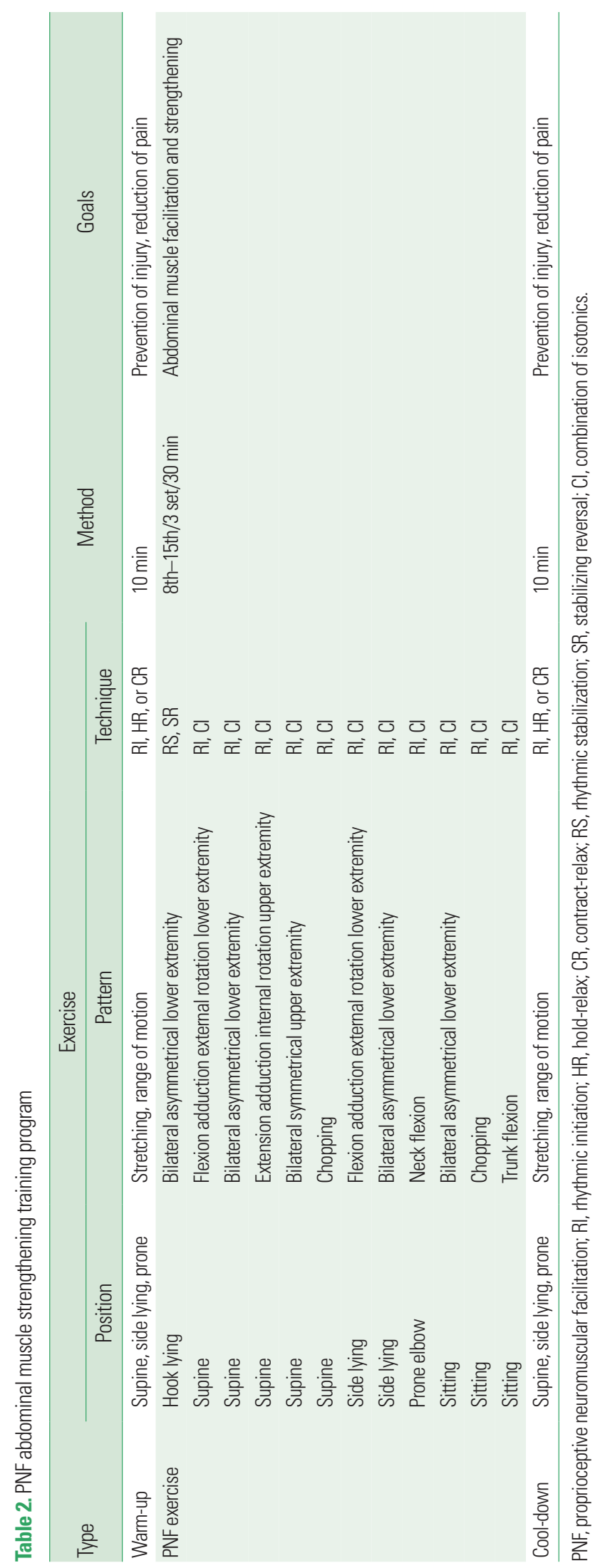


Table 3. Comparison of $\mathrm{FEV}_{1}$, VAS, and ODI values between the experimental and control groups $(\mathrm{n}=30)$

\begin{tabular}{|c|c|c|c|c|c|c|c|}
\hline \multirow{2}{*}{ Variable } & \multicolumn{2}{|c|}{ Experimental group $(n=15)$} & \multicolumn{2}{|c|}{ Control group $(n=15)$} & \multirow{2}{*}{$t$} & \multicolumn{2}{|c|}{ Between groups } \\
\hline & Pretest & Posttest & Pretest & Posttest & & $95 \% \mathrm{Cl}$ & $P$-value \\
\hline $\mathrm{FEV}_{1}(\mathrm{~L})$ & $3.18 \pm 0.44$ & $3.82 \pm 0.36^{*, t}$ & $3.20 \pm 0.58$ & $3.23 \pm 0.62$ & 3.19 & $0.21-0.97$ & $0.00^{*}$ \\
\hline VAS (score) & $6.60 \pm 1.12$ & $2.40 \pm 0.54^{*, t}$ & $6.53 \pm 1.11$ & $4.57 \pm 0.90^{*}$ & -7.97 & -2.72 to -1.61 & $0.00^{*}$ \\
\hline ODI (score) & $33.27 \pm 6.76$ & $21.27 \pm 3.37^{*, t}$ & $33.53 \pm 4.75$ & $28.93 \pm 4.61^{*}$ & -5.20 & -10.68 to -4.65 & $0.00^{*}$ \\
\hline
\end{tabular}

Values are presented as mean \pm standard deviation.

$\mathrm{FEV}_{1}$, forced expiratory volume at 1 second; $\mathrm{VAS}$, visual analog scale; ODI, Oswestry Disability Index.

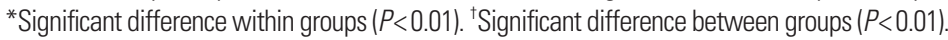

in patients' caregivers with CLBP. They found that AMST was required for at least 5 days in order to significantly reduce VAS and improve $\mathrm{FEV}_{1}$. Lee (2012) measured $\mathrm{FEV}_{1}$ according to the presence or absence of AM contractions in 20 college women and found a significant improvement in $\mathrm{FEV}_{1}$ when $\mathrm{AM}$ were contracted. In a study by Kang et al. (2015) on stroke patients, the experimental group with AMST was found to have improved $\mathrm{FEV}_{1}$ compared to the control group, which focused on trunk stability. From these studies, we can see that AMST is needed to improve pulmonary function, especially $\mathrm{FEV}_{1}$. In this study, $\mathrm{FEV}_{1}$ in the PNF-AMST (experimental) group was significantly improved by the intervention $(P<0.01)$. Also, there was a significant difference in $\mathrm{FEV}_{1}$ between the two groups $(P<0.01)$. There was a slight difference in the exercise method, similar to previous studies, but it was possible to support PNF-AMST using patterns and techniques at various positions for AM facilitation and strengthening. The reason for this is the effect of motor control and learning due to the contraction force and increased strength of the forced expiratory muscles rectus abdominis, external and internal oblique AMs, and transversus abdominis due to repeated PNF-AMST.

In a study by Jeon and Lee (2009), the PNF exercise group (30 patients with CLBP), which performed the PNF chopping and lifting pattern 3 times a week for 6 weeks, showed a significant improvement in VAS in comparison with before the intervention and with the control group. Kim et al. (2011) randomized 30 CLBP patients to the control group (I), core exercise group (II), and PNF core exercise group (III). After 4 weeks of intervention (5 times a week), VAS was significantly improved in groups II and III in comparison with before the intervention. There was a significant difference between group I and groups II and III in a post boc comparison. Lee et al. (2014b) randomized 40 production workers with CLBP to the PNF exercise group and the ball exercise group. After 6 weeks of intervention, VAS was significantly improved in both groups in comparison with before the intervention. There was no significant difference between the two exercise groups at 2 and 4 weeks, but there was a significant improvement in the PNF exercise group compared with the ball exercise group at 6 weeks. In our current study, VAS was significantly improved by the intervention in the PNF-AMST group $(P<0.01)$. Also, there was a significant difference between the PNF-AMST and control groups $(P<0.01)$. These results suggest that $\mathrm{AM}$ are activated through PNF-AMST, tone is relaxed in low back muscles, and lumbar muscles are balanced to reduce load on vertebral muscles.

Park and Seo (2014) showed a significant improvement in ODI preintervention and postintervention and in intergroup comparisons in the experimental group of 30 obese men with CLBP who underwent PNF scapular and pelvic patterns 3 times a week for 4 weeks. Park and Wang (2015) conducted KEOMT (KaltenbornEvjenth orthopedic manual therapy) and PNF techniques 3 times a week for 4 weeks in CLBP patients and found a significant improvement in ODI before and after the intervention. In 24 patients with CLBP, Kim et al. (2014) found that ODI was significantly improved in the PNF exercise group both in comparison with before the intervention and with control the group; in that study, the PNF exercise group performed PNF sprinter and skater training 5 times a week for 6 weeks. In our current study, ODI in the PNF-AMST group was significantly improved by the intervention $(P<0.01)$. Also, there was a significant difference between the PNF-AMST and control groups $(P<0.01)$. These results indicate that PNF-AMST enhances deep stabilizing muscles and affects the functional recovery of AM, thereby reducing transmission of stimuli from tissue surrounding the vertebrae, joint capsule, ligament, and other pain receptor systems.

In this study, PNF-AMST was effective in enhancing pulmonary function by AM-fortified forced expiratory muscles. Due to active contraction, the improvement in AM strength not only relieved CLBP but also prevented its recurrence as trunk stability was improved. CLBP prevention is a very important factor. Based on these results, we expect that a steady study will be needed to strengthen AM using PNF in the future. 


\section{CONFLICT OF INTEREST}

No potential conflict of interest relevant to this article was reported.

\section{REFERENCES}

Bach JR, Smith WH, Michaels J, Saporito L, Alba AS, Dayal R, Pan J. Airway secretion clearance by mechanical exsufflation for post-poliomyelitis ventilator-assisted individuals. Arch Phys Med Rehabil 1993; 74:170-177.

Fairbank JC. Oswestry disability index. J Neurosurg Spine 2014;20:239241.

Hildenbrand K, Noble L. Abdominal Muscle Activity While Performing Trunk-Flexion Exercises Using the Ab Roller, ABslide, FitBall, and Conventionally Performed Trunk Curls. J Athl Train 2004;39:37-43.

Jeon HJ, Lee MH. The effects of PNF technique versus trunk exercise program on the pain, disability, and balance in chronic LBP patients. J Korea Content Assoc 2009;9:665-673.

Kang JI, Kim BR, Park SK, Yang DJ, Jeong DK, Kim JH. Effects of deep abdominal muscle strengthening exercises on pulmonary function and the ability to balance in stroke patients. J Korean Phys Ther 2015;27: 258-263.

Kim GY, Ahn CS, Kim SS. The effects of 3-dimensional lumbar stabilization exercise have an effect on the improvement of pain and static or dynamic balance ability in 20's age group with low back pain. J Korean Soc Phys Med 2011;6:235-246.

Kim K, Kim EK, Lee DK. Effects of PNF patterns exercise on pain, functional disability and fear avoidance belief in chronic low back pain patients. J Korean Soc Phys Ther 2014;26:110-116.

Kim KS, Kwon OY, Yi CH. Effect of abdominal drawing-in maneuver on peak expiratory flow, forced expiratory volume in 1 second and pain during forced expiratory pulmonary function test in patients with chronic low back pain. J Korean Acad Univ Trained Phys Ther 2009; 16:10-17.

Kofotolis N, Kellis E. Effects of two 4-week proprioceptive neuromuscular facilitation programs on muscle endurance, flexibility, and functional performance in women with chronic low back pain. Phys Ther 2006;86:1001-1012.

Lee BK. The effect of the forced pulmonary function of young female, by changes in lung function related to postures and by transverse ab- dominis activation in standing position. J Korean Soc Phys Med 2012;7:267-274

Lee BK, Jee YS, Ko IG, Kim EK, Lee JC. Effects of combined exercises of walking and lumber stabilization on pulmonary function and lumbar deep muscles of patients with chronic low back pain. Korean J Health Promot Dis Prev 2008;8:168-177.

Lee C, Kim H, Lee I. The effect of horse-riding exercise on the balance ability in the chronic low back pain patients. J Korean Soc Integr Med 2014a;2:101-108.

Lee CW, Hwangbo K, Lee IS. The effects of combination patterns of proprioceptive neuromuscular facilitation and ball exercise on pain and muscle activity of chronic low back pain patients. J Phys Ther Sci 2014b;26:93-96.

Lee P, Helewa A, Goldsmith CH, Smythe HA, Stitt LW. Low back pain: prevalence and risk factors in an industrial setting. J Rheumatol 2001; 28:346-351.

Lingjaerde O, Føreland AR. Direct assessment of improvement in winter depression with a visual analogue scale: high reliability and validity. Psychiatry Res 1998;81:387-392.

Nachemson AL. Disc pressure measurements. Spine (Phila Pa 1976) 1981; 6:93-97.

Nourbakhsh MR, Arab AM. Relationship between mechanical factors and incidence of low back pain. J Orthop Sports Phys Ther 2002;32: $447-460$.

O'Sullivan PB. Lumbar segmental 'instability': clinical presentation and specific stabilizing exercise management. Man Ther 2000;5:2-12

Park K, Seo K. The Effects on the Pain Index and Lumbar Flexibility of Obese Patients with Low Back Pain after PNF Scapular and PNF Pelvic Patterns. J Phys Ther Sci 2014;26:1571-1574.

Park SE, Wang JS. Effect of joint mobilization using KEOMT and PNF on a patient with CLBP and a lumbar transitional vertebra: a case study. J Phys Ther Sci 2015;27:1629-1632.

Ralston SH, Urquhart GD, Brzeski M, Sturrock RD. Prevalence of vertebral compression fractures due to osteoporosis in ankylosing spondylitis. BMJ 1990;300:563-565.

Rone-Adams SA, Shamus E, Hileman M. Physical therapists evaluation of the trunk flexors in patients with low back pain. Internet J Allied Health Sci Pract 2004;2:1-9.

Yoo B, Park H, Heo K, Lee J, Lee J, Oh T, Han D. The Effects of Abdominal Hollowing in Lower-limb PNF Pattern Training on the Activation of Contralateral Muscles. J Phys Ther Sci 2013;25:1335-1338. 